\title{
Role of inducible nitric oxide synthase in asthma risk and lung function growth during adolescence
}

\author{
Talat Islam, ${ }^{1}$ Carrie Breton, ${ }^{1}$ Muhammad T Salam, ${ }^{1}$ Rob McConnell, ${ }^{1}$ Made Wenten, \\ W James Gauderman, ${ }^{1}$ David Conti, ${ }^{1}$ David Van Den Berg, ${ }^{2}$ John M Peters, ${ }^{1}$ \\ Frank D Gilliland ${ }^{1}$
}

\begin{abstract}
- Supplementary materials and tables are published online only at http://thx.bmj.com/content/ vol65/issue2
\end{abstract}

${ }^{1}$ Department of Preventive Medicine, Keck School of Medicine, University of Southern California, Los Angeles, California, USA ${ }^{2}$ Department of Urology, Keck School of Medicine, University of Southern California, Los Angeles, California, USA

\section{Correspondence to}

Professor Talat Islam, Department of Preventive Medicine, USC Keck School of Medicine, University of Southern California, 1540 Alcazar Street, CHP 236, Los Angeles, CA 90033, USA; islam@usc.edu.

Received 29 January 2009 Accepted 27 November 2009 Published Online First 8 December 2009

\section{ABSTRACT}

Background Inducible nitric oxide (NO) synthase (iNOS, encoded by NOS2A) produces $\mathrm{NO}$ in response to environmental stimuli, which can result in nitrosative stress. Because nitrosative stress affects respiratory health, it was hypothesised that variants in NOS $2 \mathrm{~A}$ are associated with asthma incidence and lung function growth during adolescence.

Methods In this prospective study, spirometric testing was performed at school and a presence or absence of asthma was ascertained annually by questionnaire among children participating in the Southern California Children's Health Study. 24 single nucleotide polymorphisms (SNPs) of the NOS2A region (with seven promoter SNPs in one haplotype block), spanning $20 \mathrm{~kb}$ upstream and $10 \mathrm{~kb}$ downstream were genotyped. Association between the NOS2A region and asthma or lung function growth was tested using genetic blockspecific principal component and haplotype analyses. This study was restricted to children with Latino and Caucasian ancestry for analyses of both asthma $(n=1596)$ and lung function growth $(n=2108)$.

Result A pair of "yin-yang" haplotypes in the promoter region showed strong association with new-onset asthma and lung function growth. The "yin" haplotype (h0111101) was associated with 44\% increased asthma risk $(p=0.003)$ and reduced forced expiratory volume in $1 \mathrm{~s}\left(\mathrm{FEV}_{1}\right)$ growth from 10 to 18 years of age $(-29.46 \mathrm{ml}$, $p=0.07)$, whereas the "yang"(h1000010) haplotype was associated with $23 \%$ reduced asthma risk $(p=0.13)$ and better $\mathrm{FEV}_{1}$ growth (43.84 $\mathrm{ml}, \mathrm{p}=0.01$ ). Furthermore, the increased asthma risk associated with h0111101 was restricted to children with the GSTM1 "null" genotype (interaction $p=0.002$, HR 1.89, 95\% Cl 1.34 to 2.60).

Conclusion Common haplotypes in the NOS2A promoter are associated with new-onset asthma and lung function growth. These effects are stronger in adolescents with the GSTM1 "null" genotype.

\section{INTRODUCTION}

Studies have shown that oxidative stress is an important determinant of respiratory health. ${ }^{1-3}$ Both increased incidence of asthma and reduced lung function growth during adolescence have been associated with environmental and genetic determinants of oxidative stress. ${ }^{45}$ Like reactive oxygen species (ROS), reactive nitrogen species (RNS) can also produce cellular injury through nitrosative stress. ${ }^{6}$ Inducible nitric oxide synthase (iNOS) plays an important role in determining nitrosative stress, as it produces large amounts of nitric oxide (NO) in response to environmental stimuli. ${ }^{6}$
$\mathrm{NO}$ is a gaseous signalling molecule that is involved in a spectrum of biological processes. In response to proinflammatory cytokines and lipopolysaccharides, epithelial cells and T lymphocytes produce NO through iNOS. ${ }^{6}$ NO reacts with superoxides $(\mathrm{O} \cdot)$ to form the highly reactive peroxynitrites $\left(\mathrm{ONOO}^{-}\right.$) that have been shown to produce airway inflammation ${ }^{7}$ and cause airway remodelling. ${ }^{9}$ Furthermore, the fractional concentration of $\mathrm{NO}$ in exhaled breath, a marker of airway inflammation, ${ }^{10}$ is predominantly of iNOS origin. ${ }^{11}$ Increased expression of iNOS may play a role in inflammation of the upper and lower airways, and contribute to both allergic rhinitis and asthma. ${ }^{12}$

Despite the evidence supporting the potential importance of iNOS in respiratory health, limited information is available about the role of DNA sequence variations in NOS2A that encodes iNOS. NOS2A is located at chromosome $17 \mathrm{q} 11.2-\mathrm{q} 12$, a region identified by genome-wide association tests as a possible region determining asthma and atopy. ${ }^{13}$ A large number of variants in NOS2A have been identified that have the potential to affect expression or function. The induction of NOS2A is complex, and the promoter region, which contains a number of variants, extends up to $16 \mathrm{~kb}$ upstream of the gene. ${ }^{14}$ There is limited evidence that repeat polymorphisms in the promoter region are associated with atopic conditions. ${ }^{15-18}$ In addition to the repeat polymorphisms, single nucleotide polymorphisms (SNPs) also exist in the promoter region that are not in strong linkage disequilibrium (LD) with the repeat polymorphisms. ${ }^{19}$ To date, a single study involving Czech adults reported association between SNPs in the NOS2A promoter region and atopy and asthma severity. ${ }^{16}$

In this study, we investigated the role of variations in the NOS2A gene with asthma pathogenesis and lung function growth in children. We hypothesised that genetic variants of NOS2A, especially those in the promoter region, are associated with new-onset asthma during adolescence and lower lung function growth, due to their likely effect on nitrosative stress. Assessing the effects of the NOS2A variants across these two respiratory outcomes provided an opportunity to evaluate the consistency in the findings. Furthermore, because the formation of peroxynitrite is dependent on the availability of ROS, we hypothesised that the associations between NOS2A polymorphisms and respiratory outcomes vary by genetic determinants of oxidative stress (GSTM1, GSTP1, CAT and $H M O X 1)$ that previously have been reported to be 
associated with lung function growth or asthma pathogenesis in this cohort. ${ }^{42021}$ We investigated these hypotheses in a cohort of Latino and Caucasian children who participated in the Children's Health Study (CHS). ${ }^{22} 23$ Some of the results have been reported in abstract form. ${ }^{24}$

\section{METHODS}

Further details are available in the online supplement.

\section{Subjects and materials}

Details concerning the design, methods and characteristics of the CHS cohort have been presented previously. ${ }^{22} 23$ Briefly, in 1993, fourth-, seventh- and tenth-grade children were enrolled into the study in each of 12 communities in Southern California. A second cohort of fourth-grade children was recruited from the same schools in 1996. Study subjects were followed annually until high school graduation. Detailed health and sociodemographic data were collected annually.

As in previous CHS genetic analyses, ${ }^{4}$ this study was restricted to children of Latino and Caucasian ancestry with available genetic data. The analysis of new-onset asthma included 1596 children who were free of asthma and wheeze at baseline. Similarly, ${ }^{25}$ the analysis of lung function was restricted to the two cohorts of fourth-grade children (mean age 10 years $(\mathrm{SD}=0.44)$ ) who were recruited in 1993 (cohort $1, \mathrm{n}=912)$ and 1996 (cohort 2, $\mathrm{n}=1196$ ) and had similar lung function growth patterns.

\section{New-onset asthma}

Children with no prior history of asthma at study entry who subsequently reported physician-diagnosed asthma at annual follow-up were classified as having new-onset asthma. Children were also interviewed annually about the use of inhaled medications. We defined a restricted group of new-onset cases with recent inhaler use for sensitivity analyses $(n=116)$.

\section{Lung function measurement}

Data on children's lung function were collected by trained field technicians using a standardised protocol during annual school visits. Maximal-effort spirometry and standing height and weight were measured. Details regarding the lung function testing protocol have been published previously. ${ }^{22}$ Three measures of lung function were included in this analysis: forced vital capacity (FVC), forced expiratory volume in the first second $\left(\mathrm{FEV}_{1}\right)$ and forced expiratory flow over the mid-range of expiration $\left(\mathrm{FEF}_{25-75}\right)$.

\section{NOS2A haplotype block determination}

Most of the upstream regulatory and promoter region was contained in a single block (figure 1: block 7) with a low multiallelic D' (0.34) with the adjacent block (figure 1: block 6). Blocks $1-6$ had higher multiallelic $D^{\prime}(>0.70)$. Therefore, the remaining region (blocks $1-6$ ) was analysed as two segments. The first segment was comprised of blocks $1-3$ and the second segment of blocks 4-6 (figure 1).

Haplotype frequencies of unphased NOS2A SNPs of the promoter region and the two coding segments for Latino and Caucasian subjects were estimated using tagSNPs. The estimated number of copies of each haplotype was used as a proxy for the true haplotype, a single imputation procedure that provides unbiased estimates and appropriate CIs. Four haplotypes in block 7 explained at least $97 \%$ of the variability of this block in both ethnic groups. Furthermore, a "yin-yang" pair of haplotypes (h0111101 and h1000010), two high-frequency haplotypes that have completely mismatching SNP nucleotides at every SNP location, ${ }^{28}$ explained at least $65 \%$ of the variability of this promoter block in the Latino and Caucasian population.

\section{Statistical methods}

To assess the global association of variation across the locus with asthma occurrence or lung function growth, the groups of common SNPs and haplotypes were tested using both principal component $(\mathrm{PC})^{31}$ and haplotype approaches. The statistical significance was based on the likelihood ratio tests (LRTs) comparing the full model (model with genetic data adjusted for all necessary adjustment variables) with the base model (model with all necessary adjustment variables without any genetic data). As indicated by Gauderman et al, a block-specific PC analysis was preferred over a whole locus approach. ${ }^{31}$ PCs explaining at least $80 \%$ of the variance of each of the three regions (two PCs for segment 1, four PCs for segment 2 and one PC for the promoter region block (block 7)) were modelled to determine the overall statistical significance of each region across outcomes (figure 1).

The haplotype model consisted of all the haplotypes with frequency $>5 \%$ and "other" haplotype, with the most common haplotype as the reference group. We also tested the effect of one and two copies of the identified haplotypes across the respiratory outcomes, using all other haplotypes as the reference group. After identifying a region that showed an overall statistically significant association with the respiratory outcomes, we tested associations between individual SNPs contained in that region and the respiratory outcomes. To address the issue of multiple testing of the correlated SNPs, the single SNP analyses were adjusted for multiple testing using the p_ACT method. ${ }^{32}$

\section{New-onset asthma analysis}

We fitted Cox proportional hazard regression models, with the time scale defined as the follow-up time with sex- and age(integer years) specific baseline hazards. All models were adjusted for community and ethnicity markers. Associations are expressed as $\mathrm{HR}$ and $95 \%$ CIs.

\section{Lung function analysis}

A hierarchical mixed effects model was used to relate 8-year growth in each lung function measure to NOS2A, with a basic structure that has been previously described. ${ }^{3}$ Random effects for the intercept and 8-year growth parameters were included at the subject level. We estimated and tested the effect of NOS2A on 8year lung function growth from age 10 to 18 . Because the findings were similar for all three lung function measures (online table E5), we present the results for $\mathrm{FEV}_{1}$ only.

\section{Sensitivity analyses}

Other variables available from questionnaire data were evaluated for potential confounding in both asthma and lung function models, but ultimately removed from the final analysis since they did not alter the results. Based on our previous publications, we also considered the "null" deletion of GSTM1, ${ }^{20}$ GSTP1Ile105Val, ${ }^{20}$ (GT)n repeats of HMOX1 and CAT-262C $\rightarrow \mathrm{T}^{4}$ as possible confounders.

\section{Test of heterogeneity}

To test whether other genes involved in the oxidative pathway (GSTM1, GSTP1:Ile105Val, HMOX1 and CAT) modified the association between NOS2A and respiratory outcomes, models with and without appropriate interaction terms were considered In the presence of statistically significant heterogeneity among subgroups, stratified analysis was performed. 
Figure 1 The linkage disequilibrium (LD) plot and haplotypes of the NOS2A gene (including the promoter region) for Europeans using data from the International HapMap Project. For the LD plot, the triangles represent the haplotype blocks. Haplotype frequencies within each block are shown below the blocks, and the multiallelic D' between blocks are shown between haplotypes.

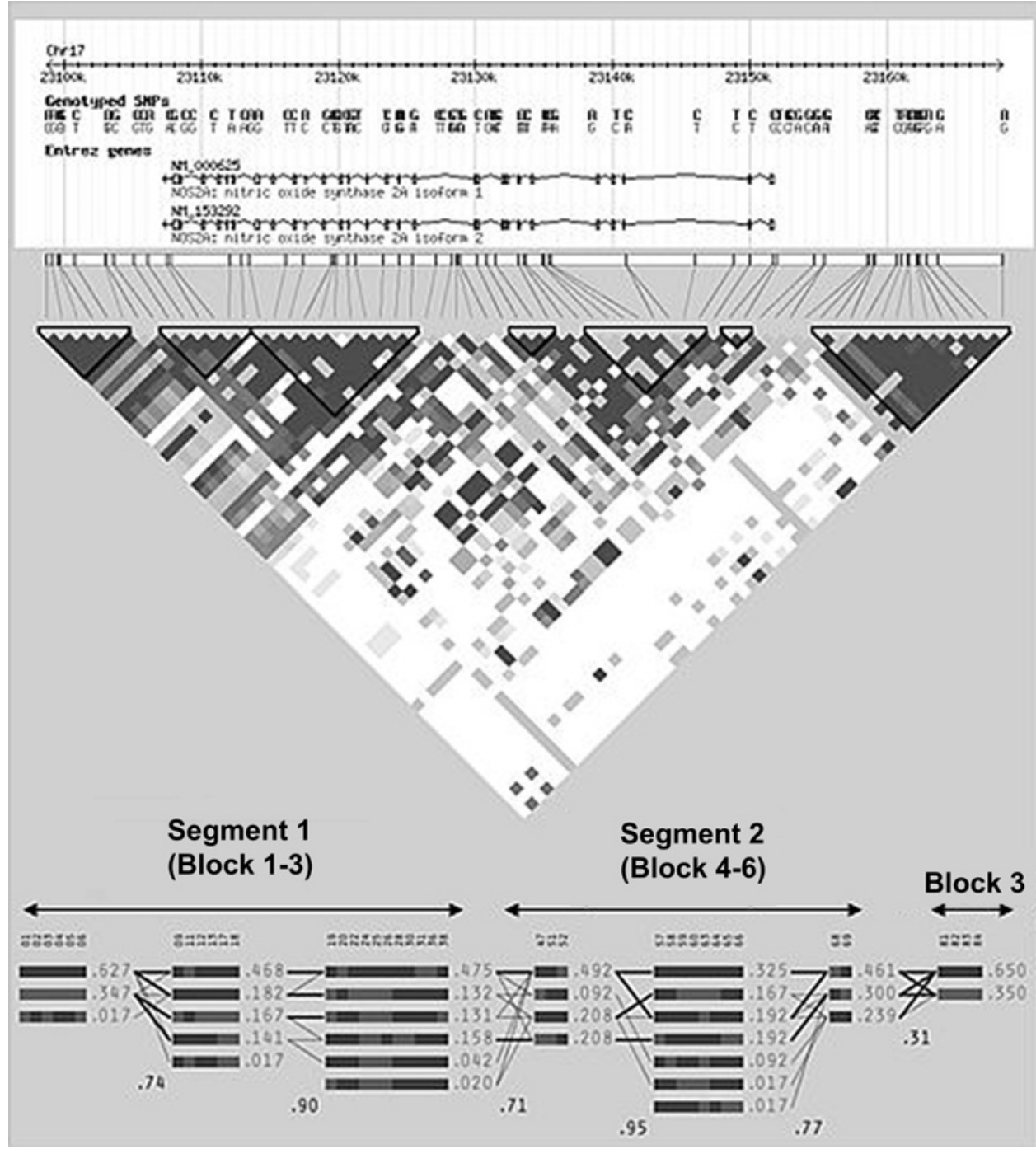

All hypothesis testing was conducted assuming a 0.05 significance level and a two-sided alternative hypothesis. All analyses were conducted using SAS software Version 9.1.3 (SAS Institute, Cary, North Carolina, USA). We used p_ACT_seq. R program in $\mathrm{R}$ software ( $\mathrm{V}$ 2.21) to address the issue of multiple testing (http://csg.sph.umich.edu/boehnke/p_act.php).

\section{RESULTS}

\section{Baseline characteristics}

The majority of children included in the asthma $(n=1596)$ or lung function $(n=2108)$ analyses were 9 years of age at study entry and of Caucasian descent (table 1). Compared with children in the asthma analysis, those in the lung function analysis were more likely to have family history of asthma $(21.7 \%$ vs $13.9 \%)$ and history of atopy (48.4\% vs $35.5 \%$ ) at baseline as the asthma analysis was restricted to children without any history of wheeze or asthma diagnosis at baseline. We did not observe any other significant differences between the two populations at baseline, and 998 children were common to both analyses.

One hundred and fifty cases of new-onset asthma were diagnosed during the follow-up period. The crude incidence rate (IR) of asthma was 16.3/100 person-years and showed little difference between Caucasians ( $\mathrm{IR}=16.1 / 1000$ person-years) and Latinos ( $I R=16.6 / 1000$ person-years). The prevalence of wheeze and prevalent asthma in the lung function analysis group was $34.7 \%$ and $15.0 \%$ at baseline, respectively. The mean $\mathrm{FEV}_{1}$ growth for boys and girls over the 8-year follow-up time was $2441 \mathrm{ml}$ and $1367 \mathrm{ml}$, respectively.

\section{MAIN EFFECT OF NOS2A}

Utilising a PC-based analysis for global tests, we observed that block 7 (containing seven SNPs of the promoter region) was associated with both an increased risk of new-onset asthma $(p=0.002)$ and decreased $F_{1}$ growth $(p=0.02)$ during adolescence (online table E6). The haplotype-based analysis for global association also showed a similar pattern of association (table 2). Compared with the common haplotype, h0111101, all other haplotypes were protective for new-onset asthma. The h0111101 haplotype was associated with increased risk of new-onset asthma (HR 1.44, 95\% CI, $\mathrm{p}=0.003$ ) and lower $\mathrm{FEV}_{1}$ growth (by $29.5 \mathrm{ml}, 95 \% \mathrm{CI}, \mathrm{p}=0.07)$ compared with all other haplotypes (table 3). This haplotype also showed a dose-dependent effect for asthma risk $(p=0.01)$. Children with one or two copies of this haplotype were at 1.49 -fold (95\% CI 1.03 to 2.14 ) and 2.08-fold (95\% CI 1.25 to 3.45 ) increased risk of new-onset asthma, respectively, compared with children without this haplotype. The other member of the "yin-yang" pair, h1000010, was associated with higher 8-year $\mathrm{FEV}_{1}$ growth $(\mathrm{p}=0.01)$ and showed a dose-dependent pattern $(\mathrm{p}=0.02)$. 
Table 1 Selected baseline characteristics of children who were included in the new-onset asthma and lung function analyses

\begin{tabular}{|c|c|c|}
\hline & $\begin{array}{l}\text { Children included in incident } \\
\text { asthma analysis }(n=1596)\end{array}$ & $\begin{array}{l}\text { Children included in LF } \\
\text { analysis }(n=2108)\end{array}$ \\
\hline \multicolumn{3}{|l|}{ Age group } \\
\hline $7-9$ years & $875(54.8)$ & $1603(76.0)$ \\
\hline $10-11$ years & $335(21.0)$ & $505(24.0)$ \\
\hline$>11$ years & $386(24.2)$ & - \\
\hline \multicolumn{3}{|l|}{ Sex } \\
\hline Girls & $894(56.0)$ & $1086(51.5)$ \\
\hline Boys & $702(44.0)$ & $1022(48.5)$ \\
\hline Latino & $554(34.7)$ & $710(33.7)$ \\
\hline Overweight & $395(24.7)$ & $536(26.5)$ \\
\hline Family history of asthma & $222(13.9)$ & $430(21.7)$ \\
\hline History of atopy* & $567(35.5)$ & $916(48.4)$ \\
\hline $\begin{array}{l}\text { History of asthma at } \\
\text { study entry }\end{array}$ & $0(0)$ & $310(12.0)$ \\
\hline Household ETS exposure & $186(19.0)$ & 361 (17.9) \\
\hline $\begin{array}{l}\text { In utero exposure to } \\
\text { smoking }\end{array}$ & $219(13.7)$ & $354(17.2)$ \\
\hline Pests of any kind & $1195(74.9)$ & $1627(83.4)$ \\
\hline Pets of any kind & $1302(81.6)$ & $1728(82.0)$ \\
\hline $\begin{array}{l}\text { Children with health } \\
\text { insurance }\end{array}$ & $1313(82.3)$ & $1781(86.3)$ \\
\hline \multicolumn{3}{|c|}{ Annual family income (in US dollars) $\dagger$} \\
\hline$\leq 14999$ & $174(10.9)$ & $263(14.3)$ \\
\hline $15000-49999$ & $584(36.6)$ & $768(41.7)$ \\
\hline$\geq 50000$ & $597(37.4)$ & $812(44.1)$ \\
\hline \multicolumn{3}{|c|}{ Highest parental education level $†$} \\
\hline Less than high school & $210(13.2)$ & $222(10.9)$ \\
\hline College & $1122(70.3)$ & $1567(74.3)$ \\
\hline Graduate & $208(13.0)$ & $242(11.9)$ \\
\hline
\end{tabular}

${ }^{*}$ Children with any history of allergy, hay fever or rhinoconjunctivitis were defined as "atopic".

†Numbers do not add up to $100 \%$ due to missing information.

ETS, environmental tobacco smoke; LF, lung function.

Compared with children not carrying this haplotype, those with one or two copies of this haplotype had $28.6 \mathrm{ml}$ (95\% CI -15.62 to 72.93 ) or $107.7 \mathrm{ml}$ (95\% CI 32.54 to 183.93$)$ higher
$\mathrm{FEV}_{1}$ growth over an 8-year period. A marginally significant protective trend for new-onset asthma was also observed among carriers of this haplotype. The risk of asthma decreased by $14 \%$ and $54 \%$ among carriers of one or two copies of the h1000010 haplotype.

\section{SNP ANALYSIS}

Investigation of the single SNPs corresponding to the haplotypes for the upstream promoter region (block 7) demonstrated significant associations (online table E7) consistent with haplotype results; therefore, we report the results from h0111101 and h1000010 analyses only.

\section{Sensitivity analysis}

The observed association between h0111101 and respiratory outcomes (new-onset asthma and $\mathrm{FEV}_{1}$ growth) were not substantially affected by adjustment for potential confounders (online tables E8 and E9: model 1). The associations between h0111101/h1000010 and respiratory outcomes were not confounded by the variants of genes involved in oxidative stress and asthma - that is, GSTM1, GSTP1, HMOX1 and CAT (online tables E8 and E9: model 2).

To assess whether the effect of the haplotypes on $\mathrm{FEV}_{1}$ growth was due to reduced lung function level in children with asthma, we investigated the effects only among children without prevalent or new-onset asthma $(n=1672)$. In this asthma-free population, the beneficial effect of h1000010 remained mostly unchanged (49.3 $\mathrm{ml}$ increase in $\mathrm{FEV}_{1}$ growth; 95\% CI 10.9 to 87.7); however, the detrimental effect of h0111101 was less pronounced ( $15.3 \mathrm{ml}$ decrease in $\mathrm{FEV}_{1} ; 95 \% \mathrm{CI}-53.9$ to 23.2).

To investigate whether the associations were consistent in independent groups of children, we performed stratified analyses for the two fourth-grade cohorts in the study populations independently recruited in 1993 and 1996. These cohorts were from the same communities and schools and thus had similar environmental exposure and socio-economic characteristics. The effect estimates for both new-onset asthma and $\mathrm{FEV}_{1}$ growth

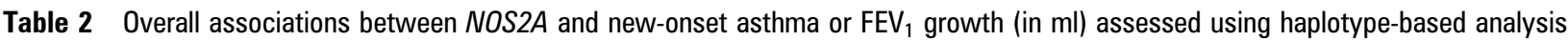

\begin{tabular}{|c|c|c|c|c|c|}
\hline \multirow{2}{*}{$\begin{array}{l}\text { NOS2A } \\
\text { region }\end{array}$} & \multirow[b]{2}{*}{ Haplotype } & \multirow{2}{*}{$\frac{\text { New-onset asthma }}{\text { HR }(95 \% \mathrm{CI}) \dagger}$} & \multicolumn{3}{|c|}{ 8-year growth in FEV 1} \\
\hline & & & p Value $\S$ & Estimate $(95 \% \mathrm{CI}) \neq$ & p Value $\S$ \\
\hline \multirow{5}{*}{$\begin{array}{l}\text { Segment } 1 \\
\text { (Blocks 1-3) }\end{array}$} & h0110010 & Ref. & \multirow[t]{5}{*}{0.06} & Ref. & \multirow[t]{5}{*}{0.46} \\
\hline & h1000000 & $0.72(0.51$ to 1.01$)$ & & $9.57(-31.99$ to 51.14$)$ & \\
\hline & h1001101 & $1.30(0.93$ to 1.8$)$ & & $27.64(-19.76$ to 75.04$)$ & \\
\hline & h0000000 & $1.00(0.71$ to 1.42$)$ & & $12.40(-34.78$ to 59.57$)$ & \\
\hline & Other* & $0.92(0.62$ to 1.37$)$ & & $-25.24(-75.13$ to 24.65$)$ & \\
\hline \multirow{9}{*}{$\begin{array}{l}\text { Segment } 2 \\
\text { (Blocks 4-6) }\end{array}$} & h0101100010 & Ref. & \multirow[t]{9}{*}{0.25} & Ref. & \multirow[t]{9}{*}{0.71} \\
\hline & h1010111001 & $1.21(0.81$ to 1.81$)$ & & $-6.64(-61.13$ to 47.84$)$ & \\
\hline & h0010000100 & $0.66(0.41$ to 1.05$)$ & & $31.86(-21.68$ to 85.40$)$ & \\
\hline & h0010000101 & $1.30(0.84$ to 2.03$)$ & & $-12.89(-74.98$ to 49.20$)$ & \\
\hline & h0101000010 & $0.79(0.48$ to 1.30$)$ & & $-32.94(-92.81$ to 26.92$)$ & \\
\hline & h0000000100 & $1.13(0.73$ to 1.74$)$ & & $-2.89(-61.28$ to 55.51$)$ & \\
\hline & h1001011001 & $1.07(0.63$ to 1.82$)$ & & $31.14(-41.84$ to 104.12$)$ & \\
\hline & h0001000001 & $0.99(0.49$ to 1.99$)$ & & $10.34(-82.78$ to 103.47$)$ & \\
\hline & Other* & $0.96(0.64$ to 1.45$)$ & & $1.07(-55.16$ to 57.30$)$ & \\
\hline \multirow[t]{5}{*}{ Block 7} & h0111101 & Ref. & \multirow[t]{5}{*}{0.02} & Ref. & \multirow[t]{5}{*}{0.10} \\
\hline & h1000010 & $0.66(0.49$ to 0.88$)$ & & $48.90(11.60$ to 86.20$)$ & \\
\hline & h0000010 & $0.84(0.60$ to 1.18$)$ & & $3.86(-41.95$ to 49.68$)$ & \\
\hline & h0000000 & $0.62(0.44$ to 0.88$)$ & & $17.04(-26.77$ to 60.85$)$ & \\
\hline & Other* & $0.85(0.42,1.74)$ & & $1.30(-107.56$ to 110.17$)$ & \\
\hline
\end{tabular}

*Haplotypes with $<5 \%$ frequencies are grouped into the "Other" category.

† HR and $95 \% \mathrm{Cl}$ are based on fitting the Cox proportional hazard model (for details see the Methods section).

‡Estimate and $95 \% \mathrm{Cl}$ are based on hierarchical mixed effects model (for details see the Methods section).

$\S p$ Values are based on a likelihood ratio test comparing models with and without genetic data.

$\mathrm{FEV}_{1}$, forced expiratory volume in $1 \mathrm{~s}$. 
were mostly similar across cohorts (online tables E3 and E4). In each of the cohorts and ethnic groups, h0111101 (online table E3) was associated with increased risk of new-onset asthma (HR range 1.2-1.7) and lower $\mathrm{FEV}_{1}$ growth $\left(\mathrm{FEV}_{1}\right.$ growth range -13.8 to $-51.8 \mathrm{ml}$ ). In contrast, h1000010 (online table E4) was associated with decreased risk of new-onset asthma (HR range 0.68-0.89) and higher $\mathrm{FEV}_{1}$ growth in all the cohorts and ethnic groups $\left(\mathrm{FEV}_{1}\right.$ growth range $\left.32.4-54.3 \mathrm{ml}\right)$.

\section{Joint effects with GSTM1 "null" status}

Lastly, we evaluated whether the association between the haplotypes of interest and respiratory disease was modified by GSTM1 status. The association between the h0111101 haplotype and new-onset asthma varied by GSTM1 "null" genotype ( $\mathrm{p}=$ 0.002 , online table 4). The increased risk of new-onset asthma for h0111101 carriers was restricted to children who lacked GSTM1 (HR 1.89, 95\% CI 1.3 to 2.6). For FEV 1 , those with the h0111101 haplotype and GSTM1 "null" genotype were also associated with the worst growth pattern ( $\mathrm{FEV}_{1}$ growth -53.19 , 95\% CI -99.63 to -6.75$)$. The protective effect of h1000010 on asthma risk or $\mathrm{FEV}_{1}$ growth did not vary by GSTM1 genotype. The haplotype effect was not modified by the presence of functional variants in other oxidative stress genes-that is, GSTP1, HMOX1 or CAT.

\section{DISCUSSION}

In this prospective study of new-onset asthma and lung function growth during childhood, we found that DNA sequence variation in the promoter region of NOS2A plays a potentially important role in respiratory health and development. We identified a pair of "yin-yang" haplotypes (h0111101 and h1000010) that accounted for $>65 \%$ of the variation in the promoter region. The "yin" haplotype (h0111101) was associated with increased risk for asthma and poor lung function growth. In contrast, the "yang" haplotype (h1000010) was associated with higher lung function and lower asthma risk. Furthermore, our analyses suggest that promoter variation in NOS2A has independent effects on asthma occurrence and lung function. These effects were consistent across two different respiratory outcomes, different internal cohorts and two different ethnic groups.

Although NOS2A has been of interest in asthma research, most of the studies did not use SNPs and none of the studies investigated its role on lung function growth. Most of the studies involved a putative functional repeat polymorphism of the promoter region, (CCTTT) $n$, that was associated with atopic status in Japanese adults, ${ }^{17}$ but not in Chinese children, ${ }^{18} \mathrm{Czech}$ adults ${ }^{16}$ or in Indian children and adults. ${ }^{15}$ In the present study, we found no evidence for an effect of this repeat polymorphism on asthma or lung function growth (data not shown). To the best of our knowledge, only one previous study has examined the role of SNPs in the promoter region on respiratory health, and associations with atopy and asthma severity were reported. ${ }^{16}$ Thus it is hard to compare our current finding with previous publications on NOS2A. However, the consistent effects of the "yin-yang" haplotypes for the two different respiratory outcomes suggest that more than one variant in this region may underlie the observed associations with asthma and lung function.

Besides being consistent across outcomes, the effects of the haplotypes were also independent of the respiratory outcomes. The detrimental effect of h0111101 and beneficial effect of h1000010 on lung function were observed among children with and without a history of asthma. Although the magnitude of the effect of the haplotypes was associated with an apparently small effect ( $1 \%$ change in lung function growth during adolescence in boys and $2 \%$ in girls), they may nevertheless play an important role in susceptible populations with low lung function levels. Furthermore, given the multifactorial nature of lung function growth and asthma, any genetic or environmental risk factors are not expected to have large individual effects.

Accumulating evidence indicates that nitrosative stress, like oxidative stress, plays an important role in airway pathobiology. ${ }^{7}$ Because the effects of variants in NOS $2 A$ on respiratory health may depend on levels of oxidative stress and gene variants in oxidant defence pathways modulate levels of oxidative stress, ${ }^{33}$ we hypothesised that NOS2A may interact with variants in oxidant defence genes such as GSTM1, which have also been associated with asthma occurrence ${ }^{21}$ and lung function growth. $^{20}$ Our observation that the detrimental effect of h0111101 on asthma risk was most apparent among children with a common GSTM1 variant lacking enzyme activity supports this hypothesis. If h0111101 results in increased NO production and formation of peroxynitrites, as we have speculated, a larger effect might be expected in GSTM1 null individuals. Lower NO production in h1000010 might result in a protective effect irrespective of GSTM1 status. Although levels of oxidative stress may be important, other pathways that involve GSTM1 may also contribute. In the current study, the NOS2A associations were independent of variation in GSTP1, HMOX1 and CAT, genes that are also involved in the oxidant defence pathways and have been shown to be associated with new-onset asthma and lung function. This implies that other functions of GSTM1, such as electrophile conjugation with

Table 3 Association between NOS2A promoter "yin-yang" haplotypes and new-onset asthma or FEV 1 growth (in ml))

\begin{tabular}{|c|c|c|c|c|c|}
\hline \multirow{2}{*}{$\begin{array}{l}\text { NOS2A } \\
\text { region }\end{array}$} & \multirow[b]{2}{*}{ Haplotype } & \multicolumn{2}{|l|}{ New-onset asthma } & \multicolumn{2}{|l|}{ 8-year growth in FEV 1} \\
\hline & & HR $(95 \%$ CI)* & p-Value $\neq$ & Estimate $(95 \% \mathrm{CI}) \dagger$ & p Value $\ddagger$ \\
\hline \multirow[t]{2}{*}{ h0111101 } & None & Ref. & 0.003 & Ref. & 0.07 \\
\hline & At least one & $1.44(1.13$ to 1.82$)$ & & $-29.46(-61.27$ to 2.36$)$ & \\
\hline \multirow[t]{4}{*}{ h0111101 } & None & Ref. & 0.01 & Ref. & 0.15 \\
\hline & One copy & $1.49(1.03$ to 2.14$)$ & & $-40.69(-85.04$ to 3.66$)$ & \\
\hline & two copies & $2.08(1.25$ to 3.45$)$ & & $-46.82(-118.29$ to 24.65$)$ & \\
\hline & None & Ref. & 0.06 & Ref. & 0.01 \\
\hline h1000010 & At least one & $0.77(0.59$ to 1.01$)$ & & 43.84 (11.39 to 76.28$)$ & \\
\hline \multirow[t]{3}{*}{ h1000010 } & None & Ref. & 0.09 & Ref. & 0.02 \\
\hline & One copy & $0.86(0.61$ to 1.21$)$ & & $28.65(-15.62$ to 72.93$)$ & \\
\hline & Two copies & $0.46(0.21$ to 1.00$)$ & & 107.74 (31.54 to 183.93 ) & \\
\hline
\end{tabular}

*HR and $95 \% \mathrm{Cl}$ are based on fitting the Cox proportional hazard model (for details see the Methods section).

†Estimate and $95 \% \mathrm{Cl}$ are based on the hierarchical mixed-effects model (for details see the Methods section).

$\neq p$ Value is based on a likelihood ratio test comparing models with and without genetic data.

$\mathrm{FEV}_{1}$, forced expiratory volume in $1 \mathrm{~s}$. 
Table 4 Association between the NOS2A promoter haplotypes and new-onset asthma or FEV 1 growth, by GSTM1 genotype

\begin{tabular}{|c|c|c|c|c|c|c|}
\hline \multirow[b]{2}{*}{ Haplotype } & \multirow[b]{2}{*}{ GSTM1 } & \multicolumn{2}{|c|}{ New-onset asthma } & \multicolumn{2}{|l|}{ 8-year growth in FEV } & \\
\hline & & HR $(95 \% \mathrm{Cl})^{*}$ & Interaction p value $\neq$ & Estimate $(95 \% \mathrm{CI}) \dagger$ & Interaction p value $\neq$ & \\
\hline \multirow[t]{3}{*}{ h0111101 } & None & Present & Ref. & 0.002 & Ref. & 0.32 \\
\hline & At least one & Present & $0.89(0.58$ to 1.37$)$ & & $-4.64(-50.20$ to 40.91$)$ & \\
\hline & At least one & Null & $1.89(1.34$ to 2.60$)$ & & $-53.19(-99.63$ to -6.75$)$ & \\
\hline \multirow[t]{3}{*}{ h1000010 } & None & Present & Ref. & 0.42 & Ref. & 0.53 \\
\hline & At least one & Present & 0.85 (0.54 to 1.34$)$ & & $39.85(-5.81$ to 85.50$)$ & \\
\hline & At least one & Null & $0.68(0.48$ to 0.98$)$ & & 49.75 (1.60 to 97.91$)$ & \\
\hline
\end{tabular}

*HR and $95 \% \mathrm{Cl}$ are based on fitting the Cox proportional hazard model (for details see the Methods section).

tEstimate and $95 \% \mathrm{Cl}$ are based on the hierarchical mixed-effects model (for details see the Methods section).

łInteraction $\mathrm{p}$ value was based on a likelihood ratio test by comparing models with and without interaction terms.

$\mathrm{FEV}_{1}$, forced expiratory volume in $1 \mathrm{~s}$.

glutathione, may be important in the interactions with NOS2A variants. As no functional data are currently available for the SNPs and the haplotypes studied, detailed sequence analyses followed by mechanistic studies examining different combination of SNPs in the region are needed to identify the specific variants that account for the haplotype associations.

One of the strengths of this study is the prospective follow-up of large numbers of school-age children with annual assessment of asthma diagnosis and lung function measurements in a consistent manner. The associations were robust and highly significant in both PC- and haplotype-based analyses, and the individual SNPs were also significant after adjusting for multiple testing using the p_ACT method. ${ }^{32}$ Furthermore, population admixture is an unlikely explanation of our findings as the incidence rate of new-onset asthma and lung function growth rate during adolescence did not vary by ethnicity and the main effects of the SNPs were similar in the ethnic-specific analysis (online tables E3 and E4). Furthermore, all analyses were adjusted for ancestry factors (based on 233 ancestry informative marker, SNPs) in addition to the traditional self-identified race identifier, thus controlling for any confounding effect of population stratification.

One potential limitation of our study, accuracy of selfreported new-onset asthma assignment, was addressed by excluding any child with a history of wheezing at study entry from the analyses to minimise any major misclassification. A recent study noted that children as young as 7 years of age can provide information regarding their asthma with an acceptable level of validity and reliability. ${ }^{34}$ Furthermore unless the diagnostic accuracy varied by genotype, error in determining asthma status would probably attenuate the risk estimates and, therefore, would not explain our observed associations. The associations were similar in sensitivity analyses restricted to cases that recently used inhaled medication and were statistically significant for the association between h1000010 and new-onset asthma (online table E8: model 3). Moreover, the observed associations of the promoter SNPs and haplotypes were consistent for lung function growth, which is an objective measurement of respiratory health and not susceptible to diagnostic or reporting bias. Therefore, our results are unlikely to be explained by misclassification of outcome.

We considered the potential effects of selection bias, as genetic data were available for about two-thirds of the initial cohort. As we have described previously, ${ }^{4}$ demographic and socio-economic factors, exposure to maternal smoking during pregnancy and secondhand smoke after birth, and household factors showed modest differences between participants and non-participants. However, adjustment for these factors did not explain our results (online table E8: model 1), indicating that selection bias based on these or related factors is unlikely to explain our findings.

We conclude that genetic variants of the NOS2A promoter region play a role in the respiratory health of children during their adolescence. The role of regulation and function of NOS2A expression in asthma pathogenesis and lung function growth and the joint effects with GSTM1 merit further investigation. Future experimental studies are necessary to define and test variants found by detailed resequencing of the promoter region of NOS $2 A$ to better understand its role in $\mathrm{NO}$ synthesis and respiratory health.

Acknowledgements We acknowledge all the participants and their parents of the CHS study, as well as all the teachers and staff of the participating schools. Without their active participation, we would not be able to address these intriguing and important aspects of respiratory health in children and adolescents. We are also grateful to the members of our experienced field team whose conscientious and courteous work ethic enabled us to gather these immense amounts of data efficiently. We also thank our colleagues who are involved in the maintenance and quality control of the database.

Funding This work was supported by the Southern California Environmental Health Sciences Center (grant \# 5P30ES007048) funded by the National Institute of Environmental Health Sciences; the Children's Environmental Health Center (grant \#s 5P01ES009581, R826708-01 and RD831861-01) funded by the National Institute of Environmental Health Sciences and the Environmental Protection Agency; the National Institute of Environmental Health Sciences (grant \# 5P01ES011627); the National Heart, Lung and Blood Institute (grant \#s 5R01HL061768 and 5R01HL076647); and the Hastings Foundation. Other funders: NIH.

\section{Competing interests None.}

Ethics This study was conducted with the approval of the University of Southern California IRB.

Provenance and peer review Not commissioned; externally peer reviewed.

\section{REFERENCES}

1. MacNee W. Oxidative stress and lung inflammation in airways disease. Eur J Pharmacol 2001;429:195-207.

2. Barnes PJ. Reactive oxygen species and airway inflammation. Free Radic Biol Med 1990:9:235-43.

3. Gauderman WJ, Avol E, Gilliland F, et al. The effect of air pollution on lung development from 10 to 18 years of age. N Engl J Med 2004;351:1057-67.

4. Islam T, McConnell R, Gauderman WJ, et al. Ozone, oxidant defense genes, and risk of asthma during adolescence. Am J Respir Crit Care Med 2008;177:388-95.

5. Islam T, Gauderman WJ, Berhane K, et al. The relationship between air pollution, lung function and asthma in adolescents. Thorax 2007;62:957-63.

6. Ricciardolo FL, Sterk PJ, Gaston B, et al. Nitric oxide in health and disease of the respiratory system. Physiol Rev 2004;84:731-65.

7. Ricciardolo FL, Di Stefano A, Sabatini F, et al. Reactive nitrogen species in the respiratory tract. Eur J Pharmacol 2006;533:240-52.

8. Gabazza EC, Taguchi 0 , Tamaki $S$, et al. Role of nitric oxide in airway remodelling. Clin Sci (Lond) 2000;98:291-4

9. Prado CM, Leick-Maldonado EA, Yano L, et al. Effects of nitric oxide synthases in chronic allergic airway inflammation and remodeling. Am J Respir Cell Mol Biol 2006;35:457-65.

10. Saito J, Sato $\mathrm{S}$, Hasunuma $\mathrm{H}$, et al. Off-line fractional exhaled nitric oxide measurement is useful to screen allergic airway inflammation in an adult population. J Asthma 2007;44:805-10. 
11. Hansel TT, Kharitonov SA, Donnelly LE, et al. A selective inhibitor of inducible nitric oxide synthase inhibits exhaled breath nitric oxide in healthy volunteers and asthmatics. FASEB J 2003;17:1298-300.

12. Yuksel H, Kirmaz C, Yilmaz 0, et al. Nasal mucosal expression of nitric oxide synthases in patients with allergic rhinitis and its relation to asthma. Ann Allergy Asthma Immunol 2008:100:12-16.

13. Dizier MH, Besse-Schmittler C, Guilloud-Bataille M, et al. Genome screen for asthma and related phenotypes in the French EGEA study. Am J Respir Crit Care Med 2000:162:1812-28.

14. de Vera ME, Shapiro RA, Nussler AK, et al. Transcriptional regulation of human inducible nitric oxide synthase (NOS2) gene by cytokines: initial analysis of the human NOS2 promoter. Proc Natl Acad Sci USA 1996;93:1054-9.

15. Batra J, Singh TP, Mabalirajan U, et al. Association of inducible nitric oxide synthase (iNOS) with asthma severity, total serum IgE and blood eosinophil levels. Thorax 2007:62:16-22.

16. Holla LI, Stejskalova A, Znojil V, et al. Analysis of the inducible nitric oxide synthase gene polymorphisms in Czech patients with atopic diseases. Clin Exp Allergy 2006;36:1592-601.

17. Konno S, Hizawa N, Yamaguchi E, et al. (CCTTT)n repeat polymorphism in the NOS2 gene promoter is associated with atopy. J Allergy Clin Immunol 2001;108:810-14.

18. Leung TF, Liu EK, Li CY, et al. Lack of association between NOS2 pentanucleotide repeat polymorphism and asthma phenotypes or exhaled nitric oxide concentration. Pediatr Pulmonol 2006:41:649-55.

19. Burgner D, Rockett K, Ackerman H, et al. Haplotypic relationship between SNP and microsatellite markers at the NOS2A locus in two populations. Genes Immun 2003:4:506-14.

20. Gilliland FD, Gauderman WJ, Vora $\mathrm{H}$, et al. Effects of glutathione-S-transferase M1, T1, and P1 on childhood lung function growth. Am J Respir Crit Care Med 2002;166:710-16.

21. Gilliland FD, Li YF, Dubeau L, et al. Effects of glutathione S-transferase M1, maternal smoking during pregnancy, and environmental tobacco smoke on asthma and wheezing in children. Am J Respir Crit Care Med 2002;166:457-63.
22. Peters JM, Avol E, Gauderman WJ, et al. A study of twelve Southern California communities with differing levels and types of air pollution. II. Effects on pulmonary function. Am J Respir Crit Care Med 1999;159:768-75.

23. Peters JM, Avol E, Navidi W, et al. A study of twelve Southern California communities with differing levels and types of air pollution. I. Prevalence of respiratory morbidity. Am J Respir Crit Care Med 1999:159:760-7.

24. Islam T, Bretton C, Salam M, et al. NOS2A polymorphisms and incident asthma. Am J Respir Crit Care Med 2008;177:A908.

25. Gauderman WJ, Vora $\mathrm{H}$, McConnell $\mathrm{R}$, et al. Effect of exposure to traffic on lung development from 10 to 18 years of age: a cohort study. Lancet 2007;369: 571-7.

26. Kolonel LN, Henderson BE, Hankin JH, et al. A multiethnic cohort in Hawaii and Los Angeles: baseline characteristics. Am J Epidemiol 2000;151:346-57.

27. Stram D0, Haiman CA, Hirschhorn JN, et al. Choosing haplotype-tagging SNPS based on unphased genotype data using a preliminary sample of unrelated subjects with an example from the Multiethnic Cohort Study. Hum Hered 2003;55:27-36.

28. Zhang J, Rowe WL, Clark AG, et al. Genomewide distribution of high-frequency, completely mismatching SNP haplotype pairs observed to be common across human populations. Am J Hum Genet 2003;73:1073-81.

29. Conti DV, Lee W, Li D, et al. Nicotinic acetylcholine receptor $\{$ beta 2 subunit gene implicated in a systems-based candidate gene study of smoking cessation. Hum $\mathrm{Mol}$ Genet 2008;17:2834-48.

30. Smith MW, Patterson N, Lautenberger JA, et al. A high-density admixture map for disease gene discovery in african americans. Am J Hum Genet 2004;74:1001-13.

31. Gauderman WJ, Murcray C, Gilliland F, et al. Testing association between disease and multiple SNPs in a candidate gene. Genet Epidemiol 2007:31:383-95.

32. Conneely KN, Boehnke M. So many correlated tests, so little time! Rapid adjustmen of $p$ values for multiple correlated tests. Am J Hum Genet 2007:81:1158-68.

33. London SJ. Gene-air pollution interactions in asthma. Proc Am Thorac Soc 2007:4:217-20.

34. Olson LM, Radecki L, Frintner MP, et al. At what age can children report dependably on their asthma health status? Pediatrics 2007;119:e93-102. 